Article

\title{
A Quinacridone-Diphenylquinoxaline-Based Copolymer for Organic Field-Effect Transistors
}

\author{
Yong Jin Jeong ${ }^{1}$, Jeong Hyun $\mathrm{Oh}^{2}$, Ho Jun Song ${ }^{3, *}$ and Tae Kyu An ${ }^{2,4, * \mathbb{C}}$ \\ 1 Department of Materials Science and Engineering, Korea National University of Transportation, \\ Chungju 27469, Korea; il5range@gmail.com \\ 2 Department of Polymer Science \& Engineering, Korea National University of Transportation, \\ Chungju 27469, Korea; i0055735@naver.com \\ 3 Research Institute of Sustainable Manufacturing System Intelligent Sustainable Materials R\&D Group, \\ Korea Institute of Industrial Technology, Chungcheongnam-do 31056, Korea \\ 4 Department of IT Convergence, Korea National University of Transportation, Chungju 27469, Korea \\ * Correspondence: song3026@kitech.re.kr (H.J.S.); taekyu1985@ut.ac.kr (T.K.A.)
}

Received: 2 March 2019; Accepted: 22 March 2019; Published: 26 March 2019

\begin{abstract}
In this work, we characterized poly(quinacridone-diphenylquinoxaline) (PQCTQx). PQCTQx was synthesized by a Suzuki coupling reaction and the synthesized PQCTQx was used as a polymeric semiconducting material in organic field-effect transistors (OFETs) to research the potential of using quinacridone derivatives. The measured field-effect mobility of the pristine PQCTQx film was $6.1 \times 10^{-3} \mathrm{~cm}^{2} /(\mathrm{V} \cdot \mathrm{s})$. A PQCTQx film heat-treated at $150{ }^{\circ} \mathrm{C}$ exhibited good field-effect performances with a hole mobility of $1.2 \times 10^{-2} \mathrm{~cm}^{2} /(\mathrm{V} \cdot \mathrm{s})$. The improved OFET behaviors resulting from the mild thermal treatment was attributed to improved packing of the molecules in the film, as determined using $\mathrm{X}$-ray diffraction, and to decreased channel resistance.
\end{abstract}

Keywords: organic field-effect transistor (OFET); organic semiconductor; quinacridone; thermal annealing; channel resistance; polymeric semiconductor

\section{Introduction}

Research into organic field-effect transistors (OFETs) has been committed to the advancement of organic semiconducting materials and device engineering technologies in the last decades [1-5]. Current investigations of OFETs are aiming to rapidly meet the rising demand for large-area or flexible sensors and displays, and driving elements for RF identification tags, as well as many other lower-cost functional devices [6,7]. While OFETs generally work best in applications that do not typically need high-performance semiconducting materials, such as single crystalline and polycrystalline silicon, high field-effect mobility and good device-to-device reproducibility (which rely partially upon the structural consistency of the OFET film) are nonetheless significant even for inexpensive electronic circuits now that the numerous transistors in these devices have to function all together [8]. To enhance OFET performance, one of the most important considerations is developing molecular design strategies aimed at enhancing the packing of the molecules in the OFET. For this purpose, various organic semiconductors have been synthesized and analyzed. The greatest advantage of using organic molecules as semiconductors is that it is easy to make planar conjugated structures out of these molecules, and such structures strongly form $\pi-\pi$ interactions and bring about fast charge transport [9].

Polymeric semiconductors, in particular, show superior mechanical flexibility and are amenable to solution processes for large areas in forming a uniform film morphology, and are hence regarded as promising candidates for active semiconducting materials in OFETs [10]. Various kinds of polymeric semiconductors have been developed, but quinacridone (QC)-based polymers have drawn particularly 
significant attention for use in organic electronic devices, because these polymers have a well-ordering structure and are able to self-assemble [11]. The quinacridone moiety has been widely studied as electron-withdrawing units and red-violet pigments in donor-acceptor (D-A) copolymers for organic solar cells and light-emitting diodes [12]. The application of a quinacridone-based polymer in light-emitting diodes was first reported by the Wang group [13].

Copolymers, including quinacridone units, may be promising candidates for using semiconducting materials in OFETs now that the quinacridone unit has a planar and simple molecular structure that can easily participate in $\pi-\pi$ interactions, and hence lead to efficient charge transport. The Fu group reported the OFET performance of quinacridone-benzothiadiazole-based D-A copolymers and showed their hole mobility values in each case to be $0.3 \mathrm{~cm}^{2} /(\mathrm{V} \cdot \mathrm{s})$ [12]. Recently, our group also reported the use of poly[quinacridone-alt-quaterthiophene] (PQCQT) and poly(quinacridone-quinoxaline) (PQCQx) as channel materials in OFETs with hole mobilities of $2.0 \times 10^{-2}$ and $1.4 \times 10^{-3} \mathrm{~cm}^{2} /(\mathrm{V} \cdot \mathrm{s})$ when using PQCQT and PQCQx [14,15]. As the field of developing quinacridone-based D-A copolymer semiconductors have progressed, it is necessary to investigate thermal stability of the quinacridone-based D-A polymer crystals and the effect of thermal annealing process on the lateral charge transports that can be evaluated from the field-effect mobility and channel resistance in the OFETs.

In this work, we characterized poly(quinacridone-diphenylquinoxaline) (PQCTQx), whose structure is shown in Figure 1, for applications in OFETs. Although PQCTQx has been investigated by the Moon group for employment in organic solar cells [16], it has not, to the best of our knowledge, been applied to a semiconducting material in OFETs. The PQCTQx OFET device exhibited p-type performance of hole mobility values of $6.5 \times 10^{-3} \mathrm{~cm}^{2} /(\mathrm{V} \cdot \mathrm{s})$ and $1.3 \times 10^{-2} \mathrm{~cm}^{2} /(\mathrm{V} \cdot \mathrm{s})$, resulting from pristine and thermally heat-treated PQCTQx films, respectively. The different OFET behaviors resulting from the pristine and heat-treated PQCTQx films we prepared were explained by the results of X-ray diffraction (XRD) and channel resistance experiments.

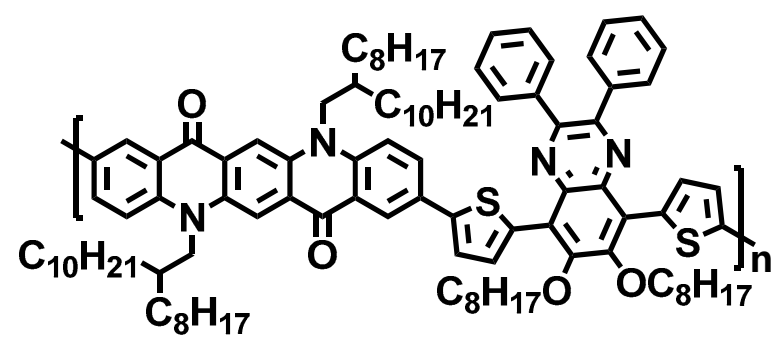

Figure 1. Molecular structure of PQCTQx.

\section{Experimental}

\subsection{Materials, Device Fabrication}

The PQCTQx was synthesized by a Suzuki coupling reaction, as reported formerly [16] (shown as Scheme 1). The synthesized PQCTQx polymer was found to have a number-average molecular weight $\left(\mathrm{M}_{\mathrm{n}}\right)$ of $85.0 \mathrm{~kg} / \mathrm{mol}$, and a polydispersity index (PDI) of 7.17, by employing gel permeation chromatography method with tetrahydrofuran at $40{ }^{\circ} \mathrm{C}$. The solution-processed PQCTQx film's electrical properties were investigated with the film in a top-contact/bottom-gate OFET configuration by using a 300-nm-thick $\mathrm{SiO}_{2}$ dielectric on an extremely doped n-Si substrate, which functioned as the gate electrode. The $\mathrm{SiO}_{2}$ dielectric was treated with an octadecyltrichlorosilane (ODTS) monolayer in the toluene solution for $90 \mathrm{~min}$ at room temperature. Solutions of the PQCTQx were made at a concentration of $0.2 \mathrm{wt} \%$ in chloroform and heated at $50{ }^{\circ} \mathrm{C}$ for $30 \mathrm{~min}$, and then filtered by using a $0.2-\mu \mathrm{m}$-pore-sized polytetrafluoroethylene membrane syringe filter. The polymer film was formed by conducting the spin coating method for $60 \mathrm{~s}$ at $2000 \mathrm{rpm}$. On top of the semiconductor layers $(100 \mathrm{~nm})$, gold source were deposited and electrodes were drained by using a patterned tungsten shadow mask 
over the PQCTQx layer. When measured, the channel length (L) and width (W) were $50 \mu \mathrm{m}$ and $1000 \mu \mathrm{m}$, respectively. The OFET devices were heat-treated at 150 and $200{ }^{\circ} \mathrm{C}$ for $10 \mathrm{~min}$. At this time, the heat treatment proceeded under a nitrogen atmosphere.
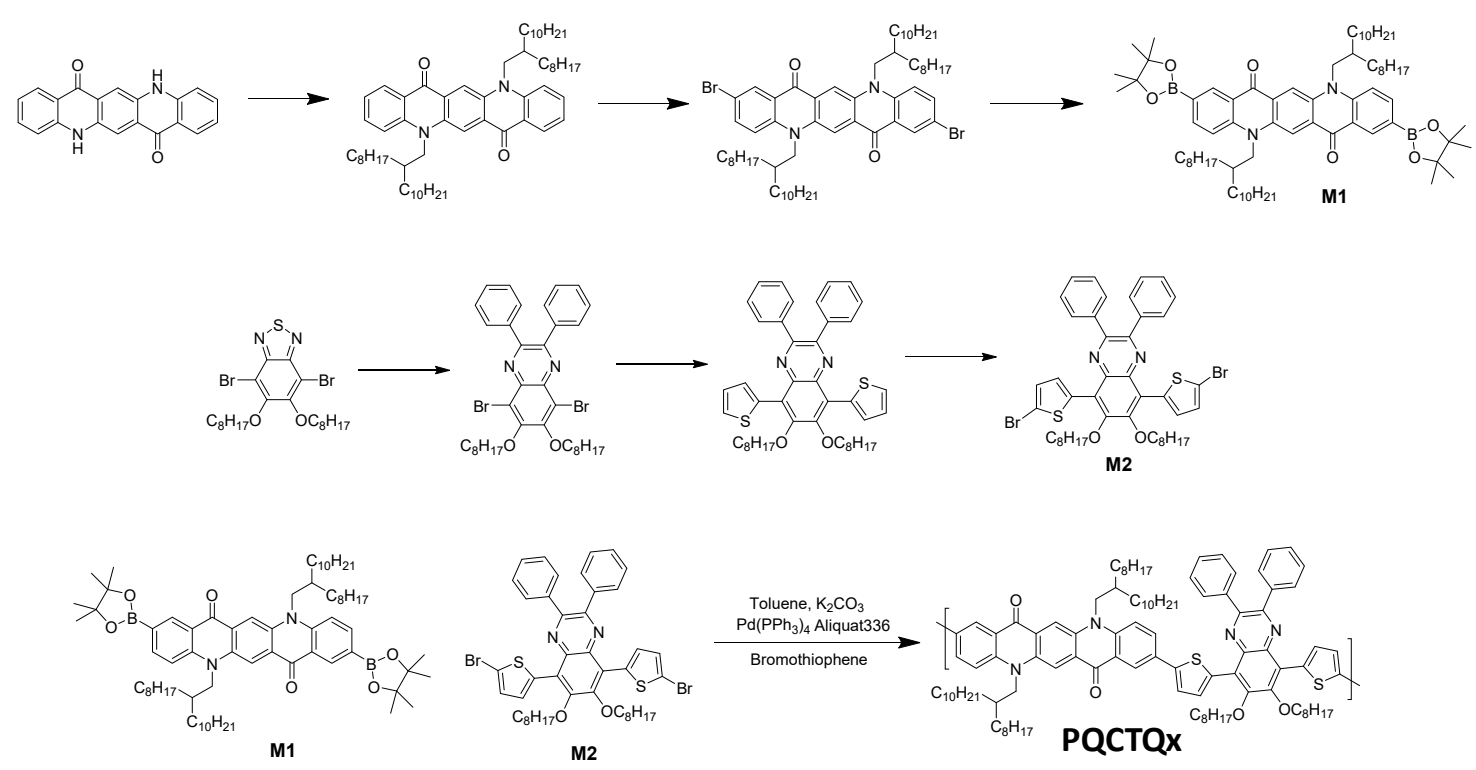

Scheme 1. Synthetic route for producing PQCTQx.

\subsection{Electrical Characterization of the OFET Devices}

Under a nitrogen atmosphere, PQCTQx OFET devices were analyzed by a Keithley 4200 SCS (Keithley Instruments, Cleveland, USA) at room temperature. Field-effect mobilities were calculated in the saturation regime from the slope of a line fitting a plot of the square root of the source-drain current $\left(I_{D S}\right)$ versus the gate voltage $\left(V_{G}\right)$; the line fitting was obtained from the equation $I_{D S}=$ $\left(W C_{i} / 2 \mathrm{~L}\right) \mu\left(V_{G}-V_{t h}\right)^{2}$, where $C_{i}$ is the capacitance per unit area of the dielectric $\left(10 \mathrm{nF} / \mathrm{cm}^{2}\right), \mu$ is the filed-effect mobility, and $V_{t h}$ is the threshold voltage. The total width-normalized channel resistances $\left(R_{\text {total }} W\right)$ were obtained from the inverse slope of the $I_{D S^{-}} V_{D}$ curves in the linear regime using output characteristics. We measured $R_{\text {total }} W$ using the output curves with $V_{G}$ of $-80 \mathrm{~V}$ applied.

\subsection{Morphological Characterization}

XRD experiments were conducted by X-rays with an energy level of $11.57 \mathrm{keV}$ at the $5 \mathrm{~A}$ beamline of the Pohang Accelerator Laboratory (PAL), Pohang, Korea. For XRD studies, the thin-film samples were prepared by spin coating method at $2000 \mathrm{rpm}$ with the $0.2 \%$ chloroform solution on an ODTS-treated Si wafer to copy the OFET device making process. To confirm the effect of thermal annealing, the some of the deposited films were heat treated at 150 and $200{ }^{\circ} \mathrm{C}$.

\section{Results and Discussion}

The transfer characteristics of the prepared PQCTQx-based OFETs are shown in Figure 2. The devices exhibited the formal p-channel transfer characteristics and the heat treatments enhanced the field-effect mobility (Table 1). The saturation field-effect mobility of the pristine PQCTQx film was extracted from the slope of the matched plot in Figure 2 to be $6.1 \times 10^{-3} \mathrm{~cm}^{2} /(\mathrm{V} \cdot \mathrm{s})$ with an on/off ratio of $1.7 \times 10^{5}$. For the heat-treated film at $150^{\circ} \mathrm{C}$, the field-effect mobility was greater, with a value of $1.2 \times 10^{-2} \mathrm{~cm}^{2} /(\mathrm{V} \cdot \mathrm{s})$, and with an on/off ratio of $3.0 \times 10^{5}$. The mobility value decreased, however, when the temperature of heat treatment was increasingly raised by $50^{\circ} \mathrm{C}$; in the heat-treated film at $200{ }^{\circ} \mathrm{C}$, the field-effect mobility was indicated to be $6.0 \times 10^{-3} \mathrm{~cm}^{2} /(\mathrm{V} \cdot \mathrm{s})$ with an on/off ratio of $5.1 \times 10^{4}$. These different OFET behaviors may have been due to structural differences between 
the as-cast and heat-treated films shown by the XRD analysis and channel resistance measurements described below.

(a)

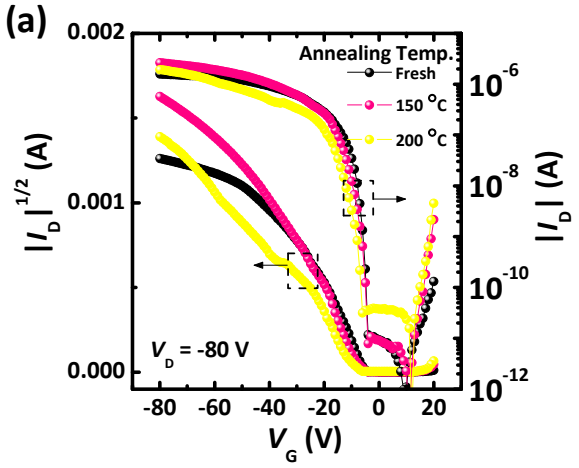

(b)

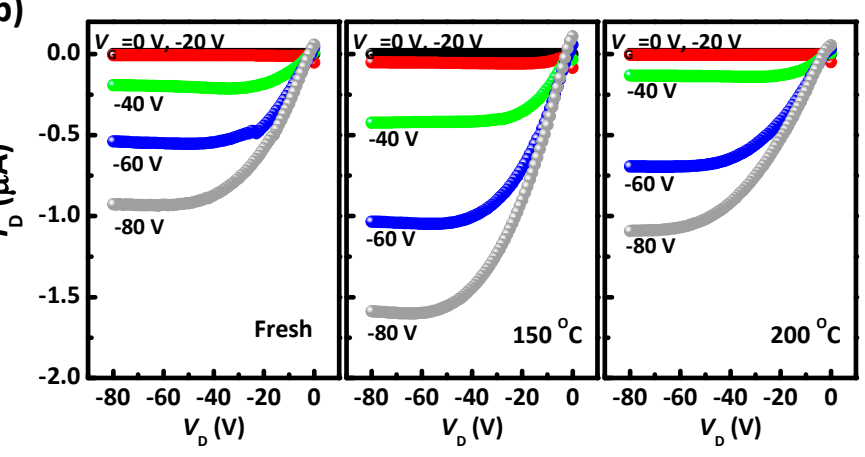

Figure 2. (a) Transfer characteristics and (b) output characteristics of the OFETs with pristine and annealed PQCTQx films.

Table 1. Performance measures of various OFETs with different PQCTQx films.

\begin{tabular}{ccccc}
\hline PQCTQx film & Mobility $\left(\mathrm{cm}^{2} / \mathrm{Vs}\right)$ & On/off & $V_{\boldsymbol{t h}}(\mathbf{V})$ & $\boldsymbol{R}_{\text {total }} \boldsymbol{W}(\mathbf{M} \Omega \mathbf{c m})$ \\
\hline As-cast & $6.1 \times 10^{-3}$ & $1.7 \times 10^{5}$ & -9.2 & 21.5 \\
Annealed at $150^{\circ} \mathrm{C}$ & $1.2 \times 10^{-2}$ & $3.0 \times 10^{6}$ & -6.3 & 16.7 \\
Annealed at $200^{\circ} \mathrm{C}$ & $6.0 \times 10^{-3}$ & $5.1 \times 10^{4}$ & -6.1 & 25.6 \\
\hline
\end{tabular}

We investigated the molecular-level structures of the PQCTQx films by using XRD. As shown in Figure 3a, the pristine PQCTQx film showed a weak (010) peak, in the out-of-plane direction of the film, and this peak was attributed to molecular stacking of $\pi-\pi$ interaction. After heat treating at $150{ }^{\circ} \mathrm{C}$, the intensity of the (010) peak increased, and indicated a $\pi-\pi$ distance of $4.0 \AA$. The XRD pattern in Figure $3 \mathrm{~b}$ revealed that the diffraction peaks seemed to appear along the in-plane direction of the pristine film, though they were not clear. After annealing at $150{ }^{\circ} \mathrm{C},(100)$ and $(010)$ peaks were observed corresponding to a d-spacing of $23.6 \AA$, showing a face-on interchain ordering. Although an edge-on structure would be expected to promote faster carrier transport along the $\pi-\pi$ stacking path in the OFET structure than would a face-on structure, a face-on structure is more suitable than an amorphous structure [17]. Previous work in our group has investigated PQCQT as the active material in OFET devices [14]. A comparison of the crystalline structures of PQCQT and PQCTQx in film state revealed that the crystalline structure of PQCTQx was not as good as that of PQCQT for charge transport in OFET devices $[17,18]$. Because the diphenylquinoxaline unit in PQCTQx is in bulky groups and generates steric hindrance, edge-on arrangement may become difficult $[19,20]$. Increasing the annealing temperature by an additional $50{ }^{\circ} \mathrm{C}$ yielded decreased intensities of the observed peaks along both (100) and (010) directions. The relatively high intensities of the PQCTQx XRD peaks subjected to thermal annealing at $150{ }^{\circ} \mathrm{C}$ suggested that this PQCTQx film was highly crystalline. The considerably crystalline structure of PQCTQx apparently induced, as described above, favorable intermolecular self-assembled interactions and efficient charge carrier transport in the PQCTQx OFETs.

Channel resistance data were also collected for the various OFET devices. The channel resistances $\left(R_{\text {total }} W\right)$ were obtained from the inverse slope of the output curves in the linear regime at $V_{G}=-80 \mathrm{~V}$. As shown in Figure 4, the channel resistance value resulting from the as-cast PQCTQx film was measured to be $21.5 \mathrm{M} \Omega \mathrm{cm}$, and the values resulting from the films annealed at $150{ }^{\circ} \mathrm{C}$ and $200{ }^{\circ} \mathrm{C}$ were measured to be $16.7 \mathrm{M} \Omega \mathrm{cm}$ and $25.6 \mathrm{M} \Omega \mathrm{cm}$, respectively. The relatively low channel resistance value resulting from the film heat treated at $150{ }^{\circ} \mathrm{C}$ led to the better field-effect mobility in its device [21,22]. 
(a)

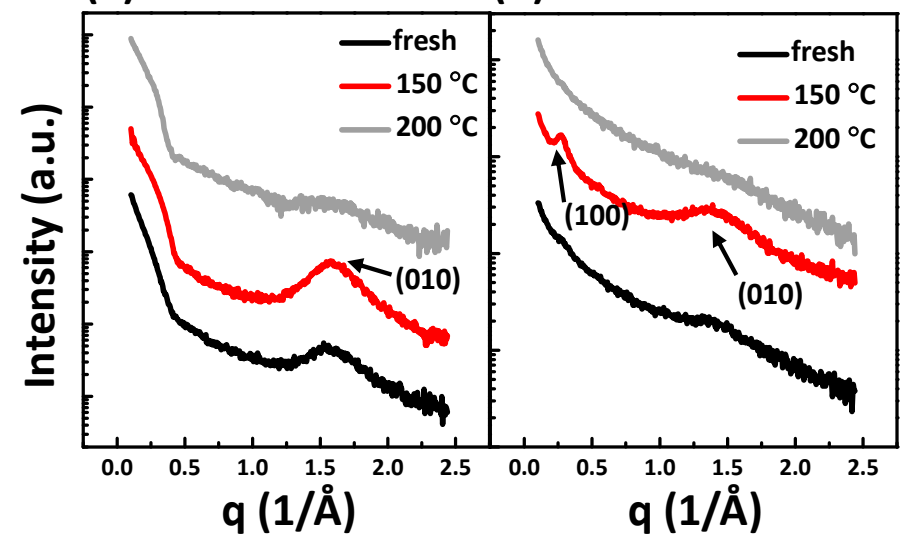

Figure 3. (a) Out-of-plane and (b) in-plane XRD patterns of the PQCTQx films.

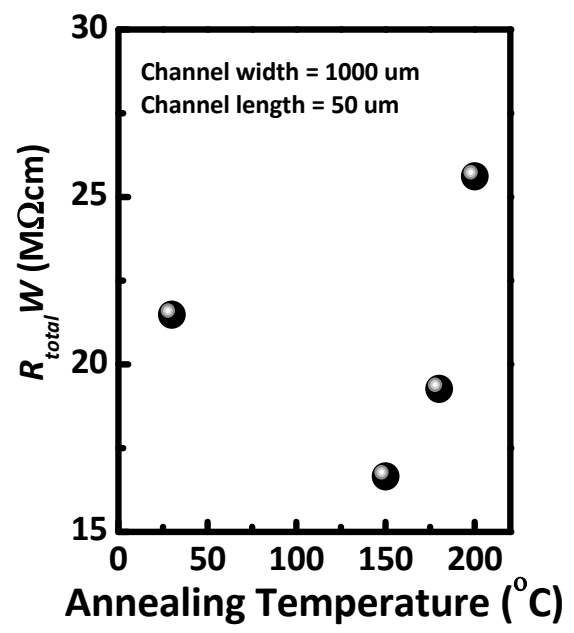

Figure 4. Dependence of the channel resistance on the annealing temperature for the PQCTQx OFET.

\section{Conclusions}

In this research, a semiconducting PQCTQx polymer based upon a diphenylquinoxaline and quinacridone unit was applied to OFET devices. A mild thermal annealing treatment improved the PQCTQx OFET performance. The PQCTQx film annealed at $150{ }^{\circ} \mathrm{C}$ exhibited a more face-on ordering structure, enhanced field-effect mobility, with a value of $1.2 \times 10^{-2} \mathrm{~cm}^{2} /(\mathrm{Vs})$, and a lower channel resistance, with a value of $16.7 \mathrm{M} \Omega \mathrm{cm}$, than did the as-cast film or the film heat treated at $200{ }^{\circ} \mathrm{C}$.

Author Contributions: Conceptualization, H.J.S. and T.K.A.; Methodology, Y.J.J.; Software, Y.J.J. and J.H.O.; Investigation, Y.J.J. and H.J.S.; Data Curation, Y.J.J. and J.H.O.; Writing-Original Draft Preparation, T.K.A.; Writing-Review \& Editing, H.J.S. and T.K.A.; Project Administration, H.J.S. and T.K.A.; Funding Acquisition, H.J.S. and T.K.A.

Funding: "This research was funded by a National Research Foundation of Korea (NRF) grant funded by the Korean government (MSIP) (2017R1C1B2002888). This research was also supported by the Industrial Strategic Technology Development Program (\#10053627) funded by the Ministry of Trade, Industry, and Energy of Korea. This research was also supported by Basic Science Research Program through the National Research Foundation of Korea(NRF) funded by the Ministry of Education(2018R1A6A1A03023788). We also acknowledge financial support for this research by the Internal Research Program of Korea Institute of Industrial Technology (PEO19280).

Acknowledgments: This research was supported by a National Research Foundation of Korea (NRF) grant funded by the Korean government (MSIP) (2017R1C1B2002888). This research was also supported by the Industrial Strategic Technology Development Program (\#10053627) funded by the Ministry of Trade, Industry, and Energy of Korea. This research was also supported by Basic Science Research Program through the National Research Foundation of Korea(NRF) funded by the Ministry of Education(2018R1A6A1A03023788). We also acknowledge financial support for this research by the Internal Research Program of Korea Institute of Industrial Technology (PEO19280). 
Conflicts of Interest: The authors declare no conflict of interest.

\section{References}

1. Ozdemir, R.; Choi, D.; Ozdemir, M.; Kwon, G.; Kim, H.; Sen, U.; Kim, C.; Usta, H. Ultralow bandgap molecular semiconductors for ambient-stable and solution-processable ambipolar organic field-effect transistors and inverters. J. Mater. Chem. C 2017, 5, 2368-2379. [CrossRef]

2. Yu, S.H.; Park, K.H.; Kim, Y.-H.; Chung, D.S.; Kwon, S.-K. Fine Molecular Tuning of DiketopyrrolopyrroleBased Polymer Semiconductors for Efficient Charge Transport: Effects of Intramolecular Conjugation Structure, Macromolecules. Macromolecules 2017, 50, 4227-4234. [CrossRef]

3. Chen, H.; Hurhangee, M.; Nikolka, M.; Zhang, W.; Kirkus, M.; Neophytou, M.; Cryer, S.J.; Harkin, D.; Hayoz, P.; Abdi-Jalebi, M.; et al. Dithiopheneindenofluorene (TIF) Semiconducting Polymers with Very High Mobility in Field-Effect Transistors. Adv. Mater. 2017, 29, 1702523. [CrossRef]

4. Kim, K.; Cho, J.; Jhon, H.; Jeon, J.; Kang, M.; Park, C.E.; Lee, J.; An, T.K. Repurposing compact discs as master molds to fabricate high-performance organic nanowire field-effect transistors. Nanotechnology 2017, 28, 205304. [CrossRef]

5. Chanwoo, Y.; Yoo, E.J.; Lee, S.W.; An, T.K.; Kim, S.H. Hybrid flexible ambipolar thin-film transistors based on pentacene and $\mathrm{ZnO}$ capable of low-voltage operation. Chin. J. Phys. 2016, 54, 471-474.

6. Root, S.E.; Savagatrup, S.; Printz, A.D.; Rodriquez, D.; Lipomi, D.J. Mechanical properties of organic semiconductors for stretchable, highly flexible, and mechanically robust electronics. Chem. Rev. 2017, 117, 6467-6499. [CrossRef] [PubMed]

7. Xu, J.; Wang, S.; Wang, G.-J.N.; Zhu, C.; Luo, S.; Jin, L.; Gu, X.; Chen, S.; Feig, V.R.; To, J.W.F.; et al. Highly stretchable polymer semiconductor films through the nanoconfinement effect. Science 2017, 335, 59-64. [CrossRef]

8. Pierre, A.; Sadeghi, M.; Payne, M.M.; Facchetti, A.; Anthony, J.E.; Arias, A.C. All-Printed Flexible Organic Transistors Enabled by Surface Tension-Guided Blade Coating. Adv. Mater. 2014, 26, 5722-5727. [CrossRef] [PubMed]

9. Jeong, N.Y.; Jang, M.S.; Park, S.M.; Chung, D.S.; Kim, Y.H.; Kwon, S.K. Synthesis and characterization of highly soluble phenanthro[1,10,9,8-c,d,e,f,g]carbazole-based copolymer: Effects of thermal treatment on crystalline order and charge carrier mobility. Dyes Pigment. 2018, 149, 560-565. [CrossRef]

10. Choi, D.; Kim, H.; Persson, N.; Chu, P.H.; Chang, M.; Kang, J.H.; Graham, S.; Reichmanis, E. ElastomerPolymer Semiconductor Blends for High-Performance Stretchable Charge Transport Networks. Chem. Mater. 2016, 28, 1196-1204. [CrossRef]

11. Osaka, I.; Akita, M.; Koganezawa, T.; Takimiya, K. Quinacridone-Based Semiconducting Polymers: Implication of Electronic Structure and Orientational Order for Charge Transport Property. Chem. Mater. 2012, 24, 1235-1243. [CrossRef]

12. Li, H.; Gu, C.; Jiang, L.; Wei, L.; Hu, W.; Fu, H. Donor-acceptor copolymers containing quinacridone and benzothiadiazole for thin film transistors. J. Mater. Chem. C 2013, 1, 2021-2027. [CrossRef]

13. Liu, J.; Gao, B.; Cheng, Y.; Xie, Z.; Geng, Y.; Wang, L.; Jing, X.; Wang, F. Novel White Electroluminescent Single Polymer Derived from Fluorene and Quinacridone. Macromolecules 2008, 41, 1162-1167. [CrossRef]

14. Jeong, Y.J.; Jeon, J.; Lee, S.; Kang, M.; Jhon, H.; Song, H.J.; Park, C.E.; An, T.K. Development of Organic Semiconductors Based on Quinacridone Derivatives for Organic Field-Effect Transistors: High-Voltage Logic Circuit Applications. IEEE J. Electron Devices Soc. 2017, 5, 209-213. [CrossRef]

15. Jeon, J.; Jhon, H.; Kang, M.; Song, H.J.; An, T.K. Quinacridone-quinoxaline-based copolymer for organic field-effect transistors and its high-voltage logic circuit operations. Org. Electron. 2018, 56, 1-4. [CrossRef]

16. Song, H.J.; Kim, D.H.; Lee, E.J.; Moon, D.K. Conjugated polymers consisting of quinacridone and quinoxaline as donor materials for organic photovoltaics: Orientation and charge transfer properties of polymers formed by phenyl structures with a quinoxaline derivative. J. Mater. Chem. A 2013, 1, 6010-6020. [CrossRef]

17. Yum, S.; An, T.K.; Wang, X.; Lee, W.; Uddin, M.A.; Kim, Y.J.; Nguyen, T.L.; Xu, S.; Hwang, S.; Park, C.E.; et al. Benzotriazole-Containing Planar Conjugated Polymers with Noncovalent Conformational Locks for Thermally Stable and Efficient Polymer Field-Effect Transistors. Chem. Mater. 2014, 26, 2147-2154. [CrossRef] 
18. Raj, M.R.; Kim, Y.; Park, C.E.; An, T.K.; Park, T. Effect of the length of a symmetric branched side chain on charge transport in thienoisoindigo-based polymer field-effect transistors. Org. Electron. 2019, 65, 251-258. [CrossRef]

19. Kawabata, K.; Saito, M.; Takemura, N.; Osaka, I.; Takimiya, K. Effects of branching position of alkyl side chains on ordering structure and charge transport property in thienothiophenedione-and quinacridone-based semiconducting polymers. Polym. J. 2017, 49, 169-176. [CrossRef]

20. Guo, X.; Puniredd, S.R.; Baumgarten, M.; Pisula, W.; Müllen, K. Rational Design of BenzotrithiopheneDiketopyrrolopyrrole-Containing Donor-Acceptor Polymers for Improved Charge Carrier Transport. Adv. Mater. 2013, 25, 5467-5472. [CrossRef] [PubMed]

21. Chesterfield, R.J.; McKeen, J.C.; Newman, C.R.; Frisbie, C.D.; Ewbank, P.C.; Mann, K.R.; Miller, L.L. Variable temperature film and contact resistance measurements on operating $\mathrm{n}$-channel organic thin film transistors. J. Appl. Phys. 2004, 95, 6396-6405. [CrossRef]

22. Jeong, Y.J.; Yun, D.J.; Jang, J.; Park, S.; An, T.K.; Kim, L.H.; Kim, S.H.; Park, C.E. Solution-processed n-type fullerene field-effect transistors prepared using CVD-grown graphene electrodes: Improving performance with thermal annealing. PCCP 2015, 17, 6635-6643. [CrossRef] [PubMed]

(C) 2019 by the authors. Licensee MDPI, Basel, Switzerland. This article is an open access article distributed under the terms and conditions of the Creative Commons Attribution (CC BY) license (http:/ / creativecommons.org/licenses/by/4.0/). 